International Journal of Management Science and Business Administration

Volume 2, Issue 10, September 2016, Pages 17-24

DOI: $10.18775 /$ ijmsba.1849-5664-5419.2014.210.1002

URL: http://dx.doi.org/10.18775/ijmsba.1849-5664-5419.2014.210.1002

\title{
Local Dilemma about Liberalisation or Intervention
}

\author{
Maris Pukis \\ Latvian Association of Local and Regional Governments, 1 Maza Pils str., LV1050 Riga, Latvia
}

\begin{abstract}
Public sector economics describes algorithms of public authorities' decisions about liberalization of their tasks or intervention in the private issues. Such theory mainly concerns national or supra-national level decisions. Aim is to propose algorithm of similar decisions locally, taking into account individual specific of local situation. Methods of policy analysis for this aim are applied. Local governments have dual nature - they are executors of national policy as well as autonomous policy-makers and executors of own policy. General principles, formally recognized by all members of the Council of Europe (this concerns $100 \%$ of the EU countries) are: 1) for dividing of competences among national and local authorities - the principle of subsidiarity; 2) for scope and content of intervention - principle of proportionality. The same principles could be applied for decisions about liberalization or intervention of local issues, which concerns obligatory or voluntary local governments' competences. Factors, which have to be taken into account to decide about intervention, are presence or absence of several types of local market failure and several types of government failure. Proposed algorithm of decision includes testing of sustainability of private activities, testing of main types of market failures, EU failure, national government failure, local government failure. That first cycle of procedure is practical implementation of the principle of subsidiarity. If intervention is necessary, then there are several options, how to impact on situation. The choice could be done among 1) regulation of private activities with corresponding administration; 2) supplying of public services for free; 3) supplying services or goods for partial payments of beneficiaries; 4) direct entrepreneurship; 5) facilitating private entrepreneurs or organized civil society organizations; 6) outsourcing of corresponding local government activities. That second cycle of procedure is practical implementation of the principle of proportionality to ensure as minimal intervention, as possible.
\end{abstract}

Keywords: Local government, Intervention, Subsidiarity, Proportionality, Failure

\section{Introduction}

There is difference between decision making about liberalization or intervention by central politicians and local politicians. That difference is based on the dividing of competences among public authorities. That difference very much depends on national traditions and diversity of values and beliefs. Question about liberalization or intervention traditionally is topic about presence or absence of market failure. The problem can be discussed also from more general point of view - taking into account main principles of public administration. Local governments have dual nature - they are executors of national policy as well as autonomous policy-makers and executors of own policy. General principles, formally recognized by all members of the Council of Europe (this also concerns $100 \%$ of the EU countries) are first, for the dividing of competencies among national and local authorities - the principle of subsidiarity; and second, for scope and content of intervention - a principle of proportionality. The same principles could be applied to decisions about liberalization or intervention of local issues, which concerns obligatory or voluntary local governments' competencies.

Public sector economics describes algorithms of public authorities' decisions about the liberalization of their tasks or intervention in the private issues. Such theory mainly concerns national or supra-national level decisions. The aim of this paper is to propose the algorithm of similar decisions locally, taking into individual account specific of the local situation. Several methods of policy analysis for this aim are applied. The experience of the Latvian Association of 
Local and Regional Governments (LALRG) to facilitate strategically management of local authorities (Pukis, 2015; LALRG, 2013) is used.

\section{Methodology}

The work on the paper was preceded by the work on amended legislation in Latvia about rights of central or local government to be an entrepreneur. Latvian legislation involves several pure neoliberal norms that public entrepreneurship is forbidden. Such legal norms come in contradiction with the principles of self-government because pluralism is a precondition of self-governance. Exemptions were connected with the presence of market failure, which is also wrong. It leads to a conclusion that there is a necessity to a multidisciplinary approach because applying only one doctrine to a disputable question is too narrow and can lead to wrong results.

Methodology of this paper is based on simultaneous applying of public administration principles of competencies dividing, public economics concepts of market failures and government failures, as well as examples of practical discussion in the local government networks of the Norway Financial Instrument project "Smart governance and Performance Improvement of Latvian Municipalities" (years 2014 and 2015). Results of policy analysis of arisen problems were discussed during International Scientific Conference in Barcelona June 2016.

\section{Theoretical Bases}

\subsection{Main Cases of Government Failure from Local Point of View}

Sources of government failure can be external to local governments (EU legislation, national legislation, regional legislation or over-bureaucratization of any of mentioned governments) as well as internal. Previous decisions of local government can be harmful from the actual point of view. Government failures can be well explained applying the theory of public choice (Buchanan, 1962).

Government failures can occur when politicians try to be popular among voters and accept policies and legislation, which is supported by the majority. Government failures can occur when bureaucrats try to be a fairy, to implement laws as much as possible. And for many other honest motives.

\subsubsection{Over-regulation}

The idea of the "state of law" is not so productive, as it looks like. European, national and regional parliaments issue new and new primary legislation, but the executive branch used to be more "productive" than parliaments to accept the new peace of secondary legislation. Increasing of the amount of different binding regulations achieve critical amount, when it leads to legal nihilism.

Multilevel governments have not enough money to fulfil requirements of the legislation. In practice, civil servants have a relatively high degree of freedom - in several cases, they act according to the requirements of the law, but in other cases do it partly, "as close as possible" to the requirements of law.

The difference between attention to regulation, based on national interests and necessity, based on local interests, are a difference between average uniform solutions and solutions, based on a full evaluation of local circumstances.

An example of over-regulation is a practice of the implementation of the EU public procurement rules in Latvia. The goal of EU is to ensure competition in the common market. Complicate procurement procedures are binding for a particular level of prices. National implementation applies those complicated procedures for much lower levels of prices; therefore administrative burden increases and local governments lose much time and money.

One of the sources for over-regulation is fundamentalism. Unlimited belief in competition is an example of fundamentalism. The balance of belief in competition and belief in protectionism is an art of politics.

\subsubsection{Harmful restrictions}

There are many different restrictions, accepted by parliamentarians to achieve ideals, beliefs and wrong economics' theories. According to public choice theory, civil servants used to support the new introduction of restrictions for their selfish interests - to increase the importance of their office. 
For example, in Latvia such harmful restrictions for local governments are:

- Prohibition to be the owner of the enterprise, except several limited cases. This means that opportunity of local government to apply in its territory reinventing government approach (Osborn, Gaebler, 1992) is under question.

- Prohibition to alienate ownership, which is necessary for the implementation of local government competencies. This means that the optimization of actions with property to decrease expenses and to increase efficiency is very limited.

- Payments for services is limited to covering of operational expenses. That leads to the necessity to cover capital investments from budget even in cases when beneficiaries are solvent etc.

\subsubsection{Excessive control}

Excessive control is based on the wrong idea that any case of law implementation has to be controlled. That leads to a tendency of an organisation of new and new government agencies or directly to increase of ministerial structures. Each of those structures invents new regulations and prepare plans of improvement of co-ordination, monitoring, audit, and punishment.

An increase of excessive control induces increase of reporting. Local governments, instead of public services supplying, spend more and more time to reports for newly organized controllers. A proportion of production of public goods is decreasing.

For example, in Latvia such excessive control is actions of State Audit Office, which deals with the same scope of auditing, as private audits, which are chosen according to the results of the competition and have 22 years practice to evaluate finance report of all local governments, their agencies, and enterprises.

A principle of subsidiarity can be used to make a choice among preserving (returning to) private responsibility or taking responsibility by local government.

\subsection{Main Cases of Market Failure from Local Point of View}

Generally, in all cases, when the market can't ensure public hopes, there is room for discussion about potential government intervention. Traditionally market failures are discussed from the national point of view - if in the national economics and through international trade corresponding good, service, workforce or capital is available, then the absence of market failure can be found.

From the local point of view, market failure means an absence of necessary goods, services or resources in local government territory. If an administration is centralized, then dominates national point of view on market failure. Policy makers discuss among themselves in wider categories - an absence of positive results in localities seems not so important and free market forces will distribute goods and resources according to demand.

Vice versa - a sense of decentralized administration is trying to develop each particular territory on the basis of competition among local governments, their residents, entrepreneurs, and their organized civil society organizations. Waiting, when market forces after 50 years will solve local problems is not way, how local politicians decide.

The decision about presence or absence of market failure is based on belief in one or another social or economic theory. Different local governments express the diversity of values. Therefore it is normal to give different answers to the same questions in different territories.

\subsubsection{Public goods}

Traditionally ideal public goods are divided from private goods by two qualities: a) availability to everywhere (or to every person, according to certain conditions); b) non-sufficiency (where use by one individual does not reduce availability to others). In practice, ideal public goods don't exist.

For example, availability of kinder-gardens is a public good, which is not entirely available in all territories of Latvia. Public good for one part of public used to be public bad for another part. Then we can speak about general public interests, which prevail under individual interests. 
In the case of local government, it is important the dependence of public good from the local interests. Representative local democracy means, that local ideas (goals, recognized by the local politicians) not always correspond to the interests of private goods, services, capital or workforce suppliers. In such cases, politicians can decide about a presence of local market failure.

So, there is a local deficit of employers, who have the capacity to facilitate structural reforms in several administrative territories of Latvia. If the local government needs to improve wealthy of its residents, then the absence of capable employees and skill workforce could be regarded as a substantial market failure.

\subsubsection{Negative externalities}

Negative externalities arise when working for profit leads to negative impact on thirst persons. In many cases, negative externalities are characteristic namely for local level. Effects, which looks not dangerous from the national point of view, can be unacceptable for local society and local elected representatives. For example, local government can exclude some economic activities by its spatial planning. That also includes private economic activities, if they are protected by national legislation and if private entrepreneurship worsens public services.

\subsubsection{Monopoly}

Monopoly arises in local level very often. Firstly, the monopoly can be based on local government decision about the organization of public utilities (natural monopoly). Privatization is allowed, but the situation does not always satisfy the hopes of residents. It could happen, then for one or another reason involvement of local government is reasonable. Nature of public authorities is service to public interests. Competition among for-profit entrepreneurs can lead to concentration of resources with an adverse effect on diversity. Local governments are normally interested in diversity as much as possible.

\subsubsection{Non-symmetric information}

Non-symmetric information is typical in the real market. Naturally, it doesn't mean that local government has to involve in any such case. For local government very principal is cases of disinformation about local government policy and about local government decisions. That leads to the necessity of active information, including not only publication of official policies, local legislative acts, and local administrative decisions, but also an explanation of reasons, goals and potential impact of local policy.

\subsubsection{Strategical interests}

Recognizing of the strategic interests of the local government as a reason for involvement in competition with the private sector is the achievement of Latvian Association of Local and Regional Governments (LALRG). The principle of self-government (Council of Europe, 1985, Art.3) is recognized by all member states of European Council, but in a majority of those states dominate central policy, strategic management of public sector is mainly recognized as the prerogative of national government.

The situation, when a diversity of politics, which may be based on diversity of ethical beliefs and diversity of economics theories, is not very characteristic. During last years LALRG develops a bench-learning method (LALRG, 2013) for facilitating an individual approach to development problems in each administrative territory.

Local governments are in permanent situation of competition with other local governments about:

- human resources (there is interest to attract smart and skilful workforce);

- central earmarked grants (to develop basic infrastructure);

- private investors (to facilitate structural changes of the local economy);

- centrally financed projects (to improve administrative capacity) etc.

\section{Application of the Legal Principles}

\subsection{Application of the Principle of Subsidiarity}

The principle of subsidiarity gives preference to decentralization. That means not disturbing private sector if the private sector is successful. That is starting point for the algorithm, (Fig.1). 
The opportunity for intervention shall be evaluated, if any kind of failure - government failure or market failure occurred. In both cases, local government decides how to improve the situation. Analysis can lead to two solutions:

1) to find legal, appropriate and effective action, which will be performed by oneself;

2) to make a proposal for appropriate changes in the state policy, national legislation or in state administrative procedures.

To improve government failure local government can perform an own action, if it concerns autonomous competences. In such case, the choice will be among actions, not forbidden to local governments by law. If there is a necessity to improve the situation with delegated competences, then local politicians can approve recommendations for central government or EU. Such recommendations can be included in the process of negotiations between local governments association and the central government.

The same concerns cases of market failures. Here problem could be "sent" to central government in two cases:

1) When action for improvement is forbidden (as in the previous case);

2) When the preference shall be for centralization.

Centralization is preferable in several cases:

1. When scope of problem is too large for one administrative territory (executive institutions are more effective in larger territory, including several or many municipalities);

2. When majority of residents believe, that equity is preferable for the content of problem, for example - in the case of socialist ideology dominance;

3. When economy of scale is applicable - calculations show, that execution in national scale will be cheaper;

4. When qualitative efficiency in the larger scale can be achieved.

The final decision, how to react to failure depends on many aspects, all forms of potential local government could be compared. A good solution can be done only after several iterations of both - subsidiarity principle and proportionality principle applying.

\subsection{Main Forms of Local Government Actions}

Local government can react to both types of failures in different ways. Depending on the purpose of analysis classification of local government actions can be different. In this case detailed classification (LALRG, 2013), which was used for application of bench-learning method to facilitate smart local government (Pukis, 2015) can be applied:

1) regulation by local legislation, when the application of those regulations is enough to decrease impact failures substantially;

2) administration of local, national or EU regulations - sometimes failures arise by the inefficient central administration, which can be improved by local attempts;

3) public services for free, if necessary public good equally relates to the majority of local government residents;

4) subsidized public services for partial payment, if participation by payments substantially increase efficiency, and public money is spent in the better way;

5) facilitating of private entrepreneurship or organized civil society organizations, that allows deforming private relations not so much, as in the case of direct involvement in the market; facilitating can be temporary and could be stopped after performing of its mission;

6) (for profit) entrepreneurship, which deforms market maximally; that form also can be evaluated as temporary - privatization after performing of its mission;

7) social entrepreneurship, when public services or social aid is provided by companies in local government ownership;

8) A public-private partnership, which allows distributing the responsibility of local government with private partners; this form allows to avoid the negative effect of public procurement rules on the efficiency of entrepreneurship (wasting public money by wasting of time, applying old-fashioned technologies, etc.);

9) Outsourcing - action, which facilitates private entrepreneurship but can deform market and can increase the expenditure of public money. 


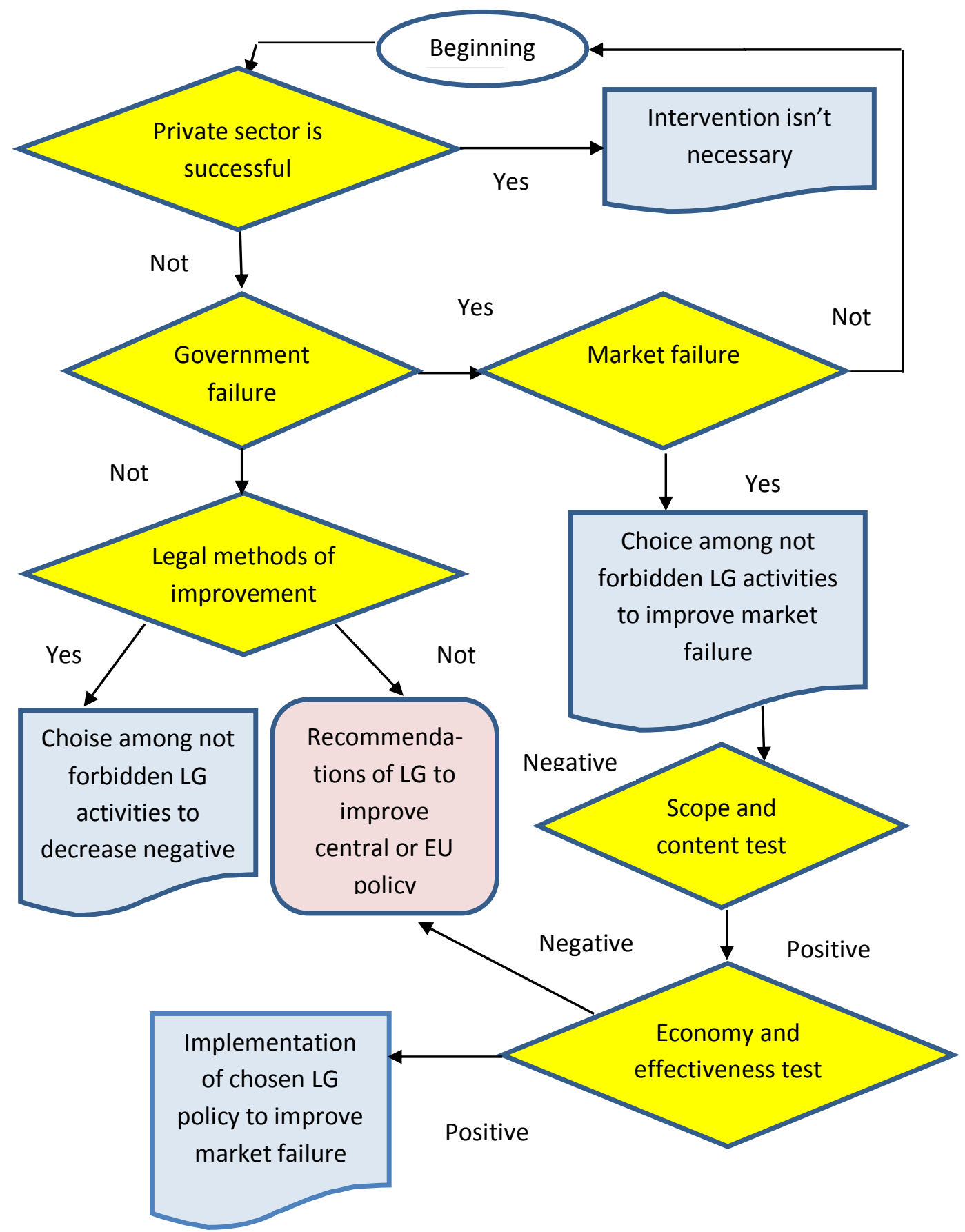

Figure.1: Applying the principle of subsidiarity for the reaction of local governments to the government failure or the market failure (Auth.)

Legal status and financing of above-mentioned nine kinds of action are different. Each of them can be used to minimize the negative impact of failures. The efficiency of those actions depends not only on external factors (which used to be similar for different municipalities) but also on internal factors (capacity of staff, available investors, etc.).

It shall be underlined, that for-profit entrepreneurship is only one of options. For example, local government owned hospitals in Latvia only formally relates to for-profit enterprises. In practice they work as social enterprises, profit is last among several goals of such activity.

Attention to for-profit public entrepreneurship depends on economic beliefs. Local government property is the collective property of the administrative territory residents, that property is a background of local governments' economics and shall be increased. For-profit entrepreneurship is a tool for communal property increasing. On another hand, local entrepreneurs traditionally think, that increasing of local government property reduce room for private property increasing. 
In any case, in lagging behind regions, local governments need to be economically more active (Council of Europe, 1998, 2002), made attention to benefits from protectionism additionally to benefits from competition. Here proportionality is the most substantial element. Decision makers had to answer the question - is an impact from intervention is proportional to achieved public benefits?

\subsection{Application of the Principle of Proportionality}

The text of Art 5, Para 4 of Treaty of the European Union (2007) shows a tendency to organize minimal public administration: "Under the principle of proportionality, the content and form of Union action shall not exceed what is necessary to achieve the objectives of the Treaties". The opposition of bureaucrats to that idea can be found, for example, in the translation of that text to Latvian (where "shall not exceed" is omitted). Fight of bureaucrats against minimalism starts from the distorting of the principles formulation.

Compliance with the principle of proportionality used to be tested by three steps Presence or absence of market failure is not sufficient for a final decision about taking responsibility by local government. Potentially applied action has to be tested to:

3) legality of public goal;

4) suitability to the approximate necessary public goal;

5) proportionality to achievable public good.

If the previously described procedure of application subsidiarity was performed, then legality is evaluated. It shall be underlined, that content of legality depends on the character of local government competence. In the case of delegated competence legality is based on national legislation - actions will be allowed by law. In the case of own, (autonomous) competence legality means, that local legislation about a potential public goal is not controversial to national or EU legislation.

Suitability to approximate necessary public goal is a good instrument to filter previously described options (types of local government actions). After that filter, only part of potential actions (among nine types, mentioned in the previous chapter) will remain.

The last element is tested proportionality applied actions to achievable public good. After the test of suitability normally will stay one or several opportunities to be compared between themselves and with current situation without changes.

The experience of Latvian local government networks (Pukis, 2015; LALRG, 2013) shows that for a majority of the local territories main problem is depopulation. Among factors, increasing negative mobility away from the territory is an old structure of local economies. Therefore, structural changes have to be facilitated. Skilled entrepreneurs and corresponding changes in the skills of the workforce are necessary.

For several territories, where interest from potential investors is small, it could be reasonable to establish municipal enterprises to attract high qualified workforce to increase of availability of such workforce in local territory. Such actions could be temporary - after increasing of perspective investors' interest local government could privatize his undertaking. In certain circumstances such intervention in the market is proportional.

For other territories, such measure is not proportional because there is interest from private entrepreneurs and necessary restructuration of local economies can be achieved by co-operation, without the artificial organization of qualified workforce demand.

\section{Conclusion}

The local dilemma about liberalization or intervention shall be solved by each local government by applying principles of subsidiarity and proportionality to local values and circumstances. The principle of subsidiarity leads to liberalization if the private sector can sufficiently solve its problems. Local governments can take responsibility in the cases when local government failure or local market failure takes place. 
The reaction of local government to government failure or market failure can be regulation, administration, providing services for free or for partial payment, facilitation of private sector activities (including privatization), for profit or social entrepreneurship, public and private partnership, outsourcing.

If the analysis shows, that central government action could be more suitable to public opinion or more effective, then the principle of subsidiarity leads to centralization. Type of local government reaction has to be chosen according to the principle of proportionality.

\section{Acknowledgement}

This research is due to support of Norway Finance Instrument project "Smart Governance and Performance Improvement of Latvian Municipalities" performed by LALRG.

\section{References}

- Buchanan J.M., Tullock G., 1962. The Calculus of Consent: Logical Foundation of Constitutional Democracy, www.econlib.org; 15.03.2016

- Council of Europe, 1985, European Charter of Local Self Government, www.coe.org; 15.03.2016

- Council of Europe, 1998, Economic Intervention by Local and Regional Authorities, No.57

- Council of Europe, 2002, Neighbourhood Services in Disadvantaged Urban Areas and in the Areas of Low Population, No.75.

- European Union, 2007, Treaty of European Union

- $\quad$ LALRG, 2013, Latvian Bench Learning Model, www.ms.lps.lv; 15.03.2016

- Osborne, David, and Ted Gaebler. 1992. Reinventing Government: How the Entrepreneurial Spirit Is Transforming the Public Sector.

- $\quad$ Pius XI, 1931, Encyclical Letter Quadragessimo Anno (May 15): AAS 23, pp.177-228

- Pukis M., 2015, Local Government Networks for Sustainable Growth of Local and Regional Economy: European Integration Studies, No.9, pp. 60-72 